\title{
A Time Series Analysis of Major Indexes Using GARCH Model with Regime Shifts
}

\author{
S. Aun Hassan ${ }^{1}$ \\ ${ }^{1}$ Hasan School of Business, Colorado State University-Pueblo, Pueblo, USA \\ Correspondence: S. Aun Hassan, Associate Professor, Hasan School of Business, Colorado State University-Pueblo, \\ 2200 Bonforte Blvd. Pueblo, CO., USA. Tel: 719-549-2201.
}

Received: September 15, 2017

Accepted: October 14, 2017

Online Published: October 17, 2017

doi:10.5430/ijfr.v8n4p127

URL: https://doi.org/10.5430/ijfr.v8n4p127

\begin{abstract}
There has always been a great interest in learning about changes in the volatility patterns of stocks and other time series due to exogenous shocks. Researchers and investors have also been curious to study the effect of unanticipated shocks on persistence of volatility over time. This paper studies three major indexes and utilizes the Iterated Cumulative Sums of Squares (ICSS) algorithm to capture time periods of sudden changes in volatility. The findings suggest that persistence of shocks to volatility is not as high as generally perceived. Volatility persistence declines significantly when regime shifts are combined with a Generalized Autoregressive Conditional Heteroskedasticity (GARCH) model. This paper provides important implications for investors and financial researchers.
\end{abstract}

Keywords: volatility, regime shifts, GARCH, ICSS algorithm

\section{JEL Classification: G1}

\section{Introduction}

Stocks have been notoriously tricky to follow and predict especially since the last stock market crash. Stock markets do seem to have recovered and have performed quite well over the past couple of years. However, it is still essential to understand how stock indexes behave over time especially when reacting to an exogenous factor. The longer the effect of an exogenous factor on a stock index, the lower would be its predicted future value as suggested by Poterba and Summers (1986). It is therefore important to accurately study the effect of these factors on the volatility of indexes. The current study examines the effect of these factors on three major indexes: Dow Jones Industrial Average (DJIA), Financial Times Stock Exchange (FTSE 100), and German Stock Index (DAX.) The paper utilizes the Iterated Cumulative Sums of Squares (ICSS) algorithm developed by Inclan and Tiao (1994) which helps locate structural breaks i.e. changes in patterns of volatility, in the return series. These structural changes are then incorporated into a Generalized Autoregressive Conditional Heteroskedasticity (GARCH) model for a more accurate estimate of persistence of exogenous shocks to the series.

\section{Literature Review}

GARCH models have been one of the most popular techniques in time series econometrics and financial economics to analyze stock markets. The GARCH model was originally developed by Bollerslev (1986) and has been frequently used ever since. Andersen and Bollerslev (1998) describe in details how ARCH models provide more accurate volatility forecasts if volatility persistence is accurately estimated. Bollerslev, Chou, and Kroner (1992) have also discussed different variants of GARCH models and their usefulness. Lastrapes (1989) used a standard ARCH model developed by Engle (1982) and found significant decrease in persistence of shocks to volatility after introducing monetary regime shifts to the model. Hamilton and Susmel (1994) used a Markov switching ARCH model while endogenously incorporating structural breaks to their model. Their results were consistent with Lastrapes's earlier study.

Caiado and Crato (2010) did a "cluster analysis" of Dow Jones Industrial Average indexes using a threshold GARCH model which is another variant of the GARCH model. Chen et al. (2008) studied the autocorrelation and conditional volatility of Dow Jones Industrial Average index return data using an exponential asymmetric GARCH model. Many earlier studies have found high persistence of shocks to volatility, suggesting that "current information remains important for the forecasts of the conditional variances for all horizons" (Engle and Bollerslev, 1986.) 
This paper focuses on the effect of sudden shifts in variance on returns series and to capture these regime shifts the ICSS algorithm that was developed by Inclan and Tiao (1994) is used. The algorithm avoids restrictive assumptions and captures variance shifts by identifying outliers as well as 'masking effects' making this a great supplement to be used with the GARCH model. Sudden changes in volatility may be the result of major political, social, and/or economic events. Charles and Darné (2014) have determined major events between 1928 and 2010 that have caused "large shocks" to the Dow Jones Industrial Average index. They have attributed these "large shocks" to financial crashes e.g. the Great Depression, wars e.g. World War II and some later wars, and monetary policies in the US. Morales and Andreosso-O'Callaghan, (2014) studied precious metal returns and three major indexes using a GARCH $(1,1)$ model and used the ICSS algorithm to capture structural breaks or sudden changes in the variance. Lobo (2002) explained how political events explained more volatility breaks as compared to economic events. Some previous studies suggest that economic events could significantly influence market portfolio. Some of the studies are dedicated towards determining major state variables. These studies include Geske and Roll, (1983) Chen, Roll, and Ross, (1986) Lee, (1992) and Thorbecke, (1997.)

In this paper, sudden changes in variance or volatility of return series are endogenously determined within the model, unlike some earlier studies. The ICSS algorithm used in this paper was also used by Aggarwal, Inclan and Leal (1999) where they explained that volatility persistence would be significantly higher if any breakpoints are ignored. The method was also used by Malik (2003) who studied exchange rates and found similar results as Aggarwal, Incan, and Leal.

\section{Estimation Methodology}

\subsection{Standard GARCH $(1,1)$ Model}

The paper attempts to measure persistence of shocks to volatility before and after introducing structural breaks to the model. In the first part of this estimation process, a standard GARCH model is estimated without including any structural breaks. The GARCH $(1,1)$ equations are described as:

$$
\begin{gathered}
\mathrm{Y}_{\mathrm{t}}=\mu+\delta \mathrm{Y}_{\mathrm{t}-1}+\varepsilon_{t} \\
\mathrm{~h}_{\mathrm{t}}=\omega+\alpha \varepsilon_{t-1}^{2}+\beta \mathrm{h}_{\mathrm{t}-1}
\end{gathered}
$$

In equation $1, \mathrm{Y}_{\mathrm{t}}$ represents the return series with error term $\varepsilon_{t}$ being normally distributed having a mean of zero. In equation $2, \mathrm{~h}_{\mathrm{t}}$ describes the conditional variance which is a function of $\omega$, the mean volatility level, $\mathrm{h}_{\mathrm{t}-1,1}$, the variance from the previous period, and $\varepsilon_{t-1}^{2}$, news from last period. The values of coefficients $\alpha$ and $\beta$ can be added to determine the persistence of shocks to volatility of each return series.

\subsection{Detecting Changes in Variance}

The ICSS algorithm has gained a lot of popularity over the years for determining structural breaks in financial time series. This paper uses the algorithm that was created by Inclan and Tiao (1994) to detect multiple changes in conditional volatility caused by exogenous shocks for each return series.

\subsection{GARCH Model with Sudden Changes}

The persistence of shocks to volatility is overestimated when standard GARCH models are used according to Lamoureux and Lastrapes (1990.) It is thereby recommended that GARCH models should incorporate any regime shifts for a more accurate estimation of persistence of shocks to variance. This is done in the second part of the estimation process as given by the modified GARCH equations:

$$
\begin{gathered}
\mathrm{Y}_{\mathrm{t}}=\mu+\delta \mathrm{Y}_{\mathrm{t}-1}+\varepsilon_{\mathrm{t}} \\
\mathrm{h}_{\mathrm{t}}=\omega+\mathrm{d}_{1} \mathrm{D}_{1}+\ldots+\mathrm{d}_{\mathrm{n}} \mathrm{D}_{\mathrm{n}}+\alpha \varepsilon_{t-1}^{2}+\beta \mathrm{h}_{\mathrm{t}-1}
\end{gathered}
$$

$\mathrm{D}_{1, \ldots}, \mathrm{D}_{\mathrm{n}}$ are dummy variables with a default zero value that changes to a value of one from each point of sudden change in variance.

\section{Data}

The paper used weekly Wednesday-close returns from January 2008 to December 2015 for DJIA (Dow Jones Industrial Average), DAX (Deutscher Aktienindex or German Stock Index), and FTSE (Financial Times Stock 
Exchange 100 Index.) Weekly data is preferred over daily data as it carries lower potential biases due to non-trading days and bid-ask effect, etc. The presence of unit root at the level form required the use of returns as recommended by the literature.

Table 1 details descriptive statistics for weekly returns. All series show negative skewness. Significant autocorrelation was detected by the Ljung-Box statistic in all index series. The DAX index has the highest Standard deviation among the three indexes which shows relatively higher volatility. The three indexes were leptokurtic (i.e. fat tails) so the mean equations were tested for autoregressive conditional heteroscedasticity (ARCH) using the test given by Engle (1982.) Based upon the results of ARCH test, the use of a GARCH model is found most appropriate.

Table 1. Descriptive statistics

\begin{tabular}{cccc}
\hline & DJIA & DAX & FTSE \\
\hline Mean & 0.000832 & 0.000777 & 0.000131 \\
Median & 0.002567 & 0.003418 & 0.002291 \\
Maximum & 0.087275 & 0.109417 & 0.068715 \\
Minimum & -0.156920 & -0.168041 & -0.127317 \\
Std. Dev. & 0.023669 & 0.032745 & 0.025373 \\
Skewness & -1.136727 & -0.977921 & -0.754056 \\
Kurtosis & 9.559245 & 6.754750 & 5.632899 \\
& & & \\
Jarque-Bera & 833.3249 & 309.9266 & 159.1967 \\
Probability & 0.0000 & 0.0000 & 0.0000 \\
Sum & 0.345101 & 0.322351 & 0.054233 \\
Sum Sq. Dev. & 0.231928 & 0.443911 & 0.266529 \\
& & & 111.65 \\
Q(16) & 136.56 & 152.74 & $(0.0000)$ \\
Observations & $(0.0000)$ & $(0.0000)$ & 415 \\
\hline
\end{tabular}

Notes: P-values in parentheses and Q(16) refers to the Ljung-Box statistics.

\section{Empirical Results}

Figure 1 shows three different graphs for each return series. Panel A shows the time periods of sudden changes in volatility as detected by the ICSS algorithm for DJIA, where as Panel B and C show these structural breaks for DAX and FTSE, respectively. DJIA shows five break points with two periods of significantly high volatility. The graphs for DAX and FTSE also show periods of high volatility around the same time. These periods of high volatility correspond to the time of the recent economic recession. 


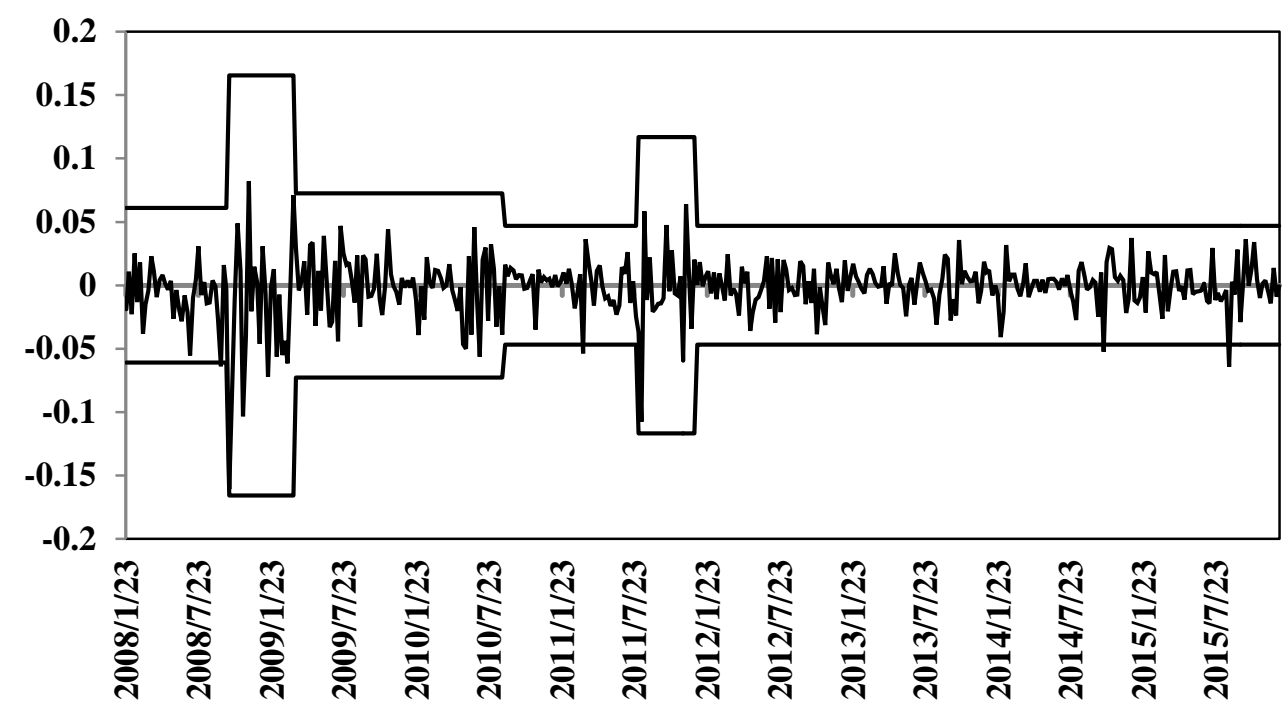

Figure 1. Graph of returns for each series (Note 1)

Panel A. Dow Jones Industrial Average - DJIA

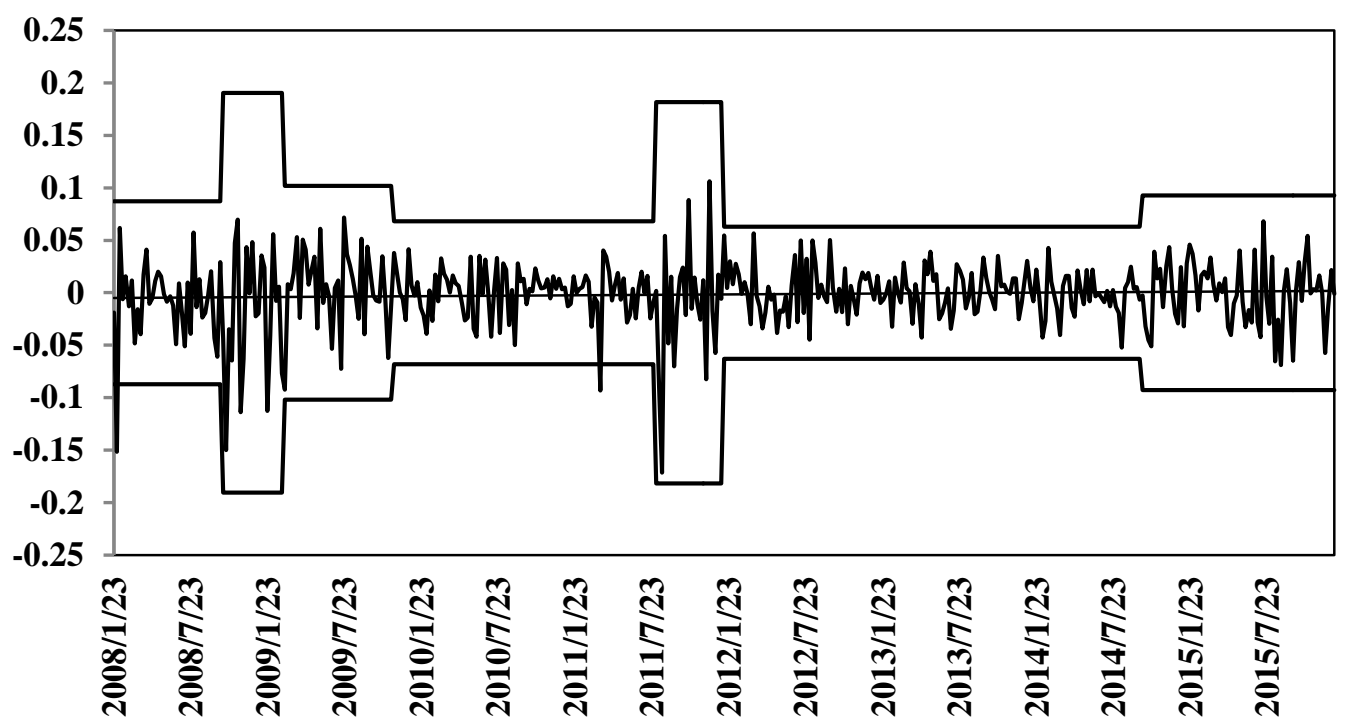

Panel B. German Stock Index - DAX 


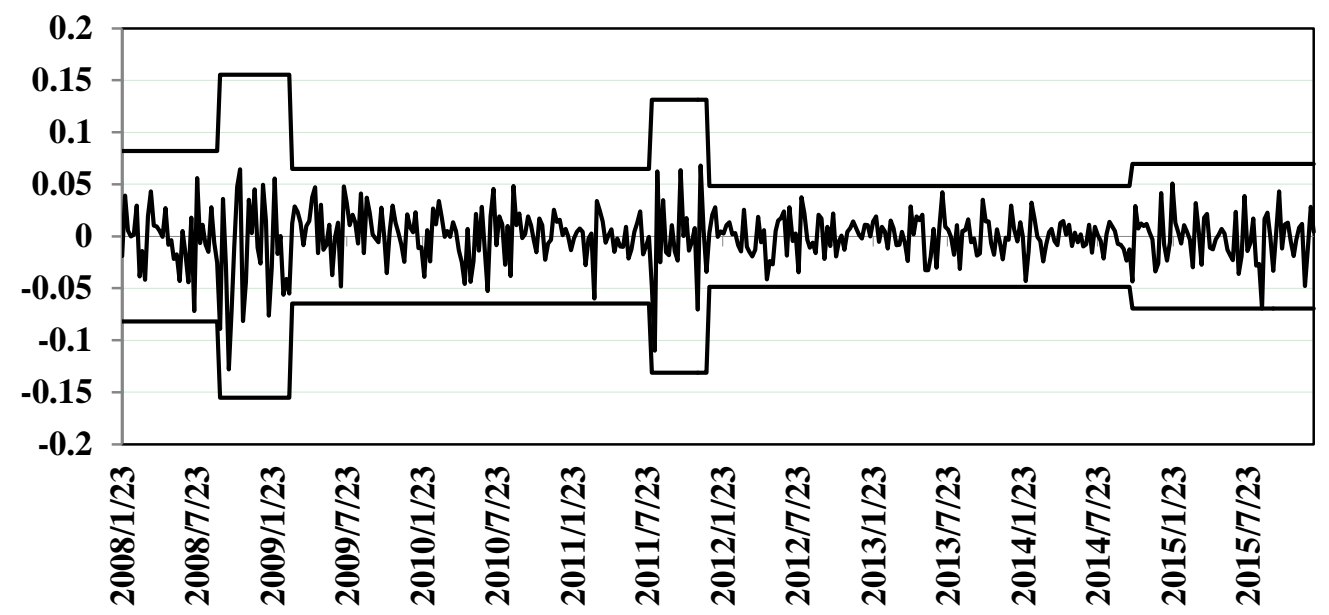

Panel C. UK Stock Index - FTSE

Table 2 also describes these structural breaks and the time points of high volatility have been marked by "**. These segments of high volatility around 2008 can be explained by the idea that financial markets faced a buying frenzy from investors in the US equity markets followed by European markets. Some of this volatility was caused by the optimism that came from better than expected growth rate of the US economy that was matched with very low rates of inflation making alternative investment options like bonds, less attractive. Another period of high volatility can be seen starting around mid-to-late 2011 which was caused by another US and global stock market crash that led to the US credit rating downgrade by Standard and Poor's. The European indexes were also influenced by the European debt crisis where several countries within the European Union were bailed-out. There is a third period of slight increase in volatility for the DAX and FTSE return series reflecting the fears of recession and other political news that did not seem to influence the DJIA index.

Table 2. Sudden changes in volatility

\begin{tabular}{|c|c|c|c|}
\hline Stock Index & $\begin{array}{c}\text { \# of Change } \\
\text { Points } \\
\end{array}$ & Time Period & $\begin{array}{l}\text { Standard } \\
\text { Deviation }\end{array}$ \\
\hline \multirow{7}{*}{ DJIA } & \multirow{7}{*}{5} & $1 / 23 / 2008-10 / 1 / 2008$ & 0.02033 \\
\hline & & $10 / 8 / 2008-3 / 18 / 2009$ & $0.05523 *$ \\
\hline & & $3 / 25 / 2009-8 / 25 / 2010$ & 0.02422 \\
\hline & & $9 / 1 / 2010-7 / 27 / 2011$ & 0.01561 \\
\hline & & $8 / 3 / 2011-12 / 21 / 2011$ & $0.03895 *$ \\
\hline & & $12 / 18 / 2011-12 / 30 / 2015$ & 0.01564 \\
\hline & & $1 / 23 / 2008-10 / 1 / 2008$ & 0.02907 \\
\hline \multirow{6}{*}{ DAX } & \multirow{6}{*}{6} & $10 / 8 / 2008-2 / 25 / 2009$ & $0.06348 *$ \\
\hline & & $3 / 4 / 2009-11 / 11 / 2009$ & 0.03397 \\
\hline & & $11 / 18 / 2009-7 / 27 / 2011$ & 0.02266 \\
\hline & & 8/3/2011 - 1/4/2012 & $0.06051 *$ \\
\hline & & $1 / 11 / 2012-9 / 24 / 2014$ & 0.02097 \\
\hline & & $10 / 1 / 2014-12 / 30 / 2015$ & 0.03088 \\
\hline \multirow{6}{*}{ FTSE } & \multirow{6}{*}{5} & $1 / 23 / 2008-9 / 10 / 2008$ & 0.02735 \\
\hline & & $9 / 17 / 2008-3 / 4 / 2009$ & $0.05175^{*}$ \\
\hline & & $3 / 11 / 2009-7 / 27 / 2011$ & 0.0216 \\
\hline & & $8 / 3 / 2011-12 / 14 / 2011$ & $0.04378 *$ \\
\hline & & $12 / 21 / 2011-10 / 8 / 2014$ & 0.01616 \\
\hline & & $10 / 15 / 2014-12 / 30 / 2015$ & 0.02314 \\
\hline
\end{tabular}

Notes: $*$ Denotes period of increased volatility. Time periods detected by ICSS algorithm. 
Some of the regime shifts identified in this paper can be associated with major social, political, and global events. However, the structural breaks may come with a lag after an event has already taken place. In some other cases however, the markets may predict major events and cause a break ahead of the event. Given these phenomena, it may be difficult to accurately associate a structural break with a major event that took place around the same time.

The values of $\alpha$ and $\beta$ are calculated using a standard GARCH model without incorporating regime shifts. The next step is to add the regime shifts into the GARCH model using dummy variables as described in the methodology section. Table 3 describes the values of $\alpha$ and $\beta$ calculated before and after the introduction of regime shifts into the GARCH model. The sum of $\alpha$ and $\beta$ describes the persistence of shocks to volatility. If the value of this sum gets closer to one, any exogenous shocks will then have a permanent effect on the volatility of return series for all future time periods. In the case of DJIA, the sum of $\alpha$ and $\beta$ is 0.93 , which is very close to one and therefore suggests that the impact of these shocks to the volatility of return series will remain for a long period of time. The situation is quite similar for DAX and FTSE as their $\alpha$ and $\beta$ values add to 0.90 and 0.95 , respectively, suggesting very high persistence of shocks to volatility.

Table 3 also shows the results of the GARCH model when regime shifts are incorporated into the estimation process. After augmenting these structural breaks into the GARCH model, the sum of $\alpha$ and $\beta$ for DJIA decreases significantly to 0.49 suggesting that the impact of shocks is relatively short-lived as compared to the results of the standard GARCH model with no dummy variables. Similar results appear for DAX and FTSE with the sums of $\alpha$ and $\beta$ coming down to 0.37 and 0.49 , respectively. All these values suggest that the effect of shocks to volatility of each return series is far less than originally perceived.

Table 3. GARCH $(1,1)$ parameters with and without dummy variables

\begin{tabular}{|c|c|c|c|c|c|c|c|c|c|c|c|}
\hline \multirow[b]{2}{*}{ Series } & \multicolumn{5}{|c|}{ GARCH $(1,1)$ Model } & \multicolumn{6}{|c|}{ GARCH $(1,1)$ Model with dummy variables } \\
\hline & $\alpha$ & $\beta$ & $\alpha+\beta$ & $\mathbf{T R}^{2}$ & $Q(16)$ & $\alpha$ & $\beta$ & $\alpha+\beta$ & $\begin{array}{l}\text { Persistence } \\
\text { decline }\end{array}$ & $\mathbf{T R}^{2}$ & $Q(16)$ \\
\hline DJIA & $\begin{array}{c}0.27 \\
(0.00)\end{array}$ & $\begin{array}{c}0.66 \\
(0.00)\end{array}$ & 0.93 & $\begin{array}{c}4.91 \\
(0.30)\end{array}$ & $\begin{array}{l}16.26 \\
(0.44)\end{array}$ & $\begin{array}{c}0.23 \\
(0.00)\end{array}$ & $\begin{array}{l}(0.32 \\
(0.05)\end{array}$ & 0.49 & 0.44 & $\begin{array}{r}4.73 \\
(0.59)\end{array}$ & $\begin{array}{l}16.46 \\
(0.42)\end{array}$ \\
\hline DAX & $\begin{array}{c}0.19 \\
(0.00)\end{array}$ & $\begin{array}{c}0.71 \\
(0.00)\end{array}$ & 0.90 & $\begin{array}{c}8.34 \\
(0.08)\end{array}$ & $\begin{array}{l}19.21 \\
(0.26)\end{array}$ & $\begin{array}{c}0.07 \\
(0.11)\end{array}$ & $\begin{array}{c}0.46 \\
(0.01)\end{array}$ & 0.53 & 0.37 & $\begin{array}{c}4.21 \\
(0.65)\end{array}$ & $\begin{array}{l}14.83 \\
(0.54)\end{array}$ \\
\hline FTSE & $\begin{array}{c}0.17 \\
(0.00)\end{array}$ & $\begin{array}{c}0.78 \\
(0.00)\end{array}$ & 0.95 & $\begin{array}{c}5.31 \\
(0.26)\end{array}$ & $\begin{array}{l}15.55 \\
(0.49)\end{array}$ & $\begin{array}{c}0.11 \\
(0.04)\end{array}$ & $\begin{array}{c}0.35 \\
(0.04)\end{array}$ & 0.46 & 0.49 & $\begin{array}{c}5.34 \\
(0.38)\end{array}$ & $\begin{array}{l}17.04 \\
(0.38)\end{array}$ \\
\hline
\end{tabular}

Notes: Q (16) is the Ljung-Box statistic and $\mathrm{TR}^{2}$ is ARCH LM test. P-values are in parentheses.

It would be reasonable to suggest that the results have major implications for investors and researchers. It is however recommended that investors should revisit their portfolios around major social, political, and global events. Similar recommendations could be made with regards to option pricing and for portfolio managers.

\section{Concluding Remarks}

This paper detects time periods of volatility shifts by using the Iterated Cumulative Sum of Squares (ICSS) algorithm for three major indexes DJIA, DAX, and FTSE and some events relative to the shifts are analyzed. A more realistic effect of these shocks to the variance is estimated by incorporating these shifts into a standard Generalized Autoregressive Conditional Heteroskedasticity $(\mathrm{GARCH})$ model. The paper finds that the persistence of shocks to volatility for each series is significantly reduced when the breaks are added to the model for estimation. The results provide an improvement over some earlier research. These findings can be useful for investors in constructing more accurate asset pricing models. The results could also help researchers make better forecasts with regards to the three stock indexes used in the study. Any studies which conclude that shocks to volatility have very high persistence for these indexes may want to consider the importance of incorporating regime shifts into their estimation. 


\section{References}

Aggarwal, R, C. Inclan, \& R. Leal. (1999). Volatility in Emerging Markets. Journal of Financial and Quantitative Analysis, 34, 33-55. https://doi.org/10.2307/2676245

Andersen, T. G., \& T. Bollerslev. (1998). Answering the Skeptics: Yes, Standard Volatility Models do Provide Accurate Forecasts. International Economic Review, 39, 885-905. https://doi.org/10.2307/2527343

Bollerslev, T. (1986). Generalized Autoregressive Conditional Heteroscedasticity. Journal of Econometrics, 31, 307-327. https://doi.org/10.1016/0304-4076(86)90063-1

Bollerslev, T., R. Y. Chou, \& K. F. Kroner. (1992). ARCH Modeling in Finance: A Review of the Theory and Empirical Evidence. Journal of Econometrics, 52, 5-59. https://doi.org/10.1016/0304-4076(92)90064-X

Caiado, J., \& Crato, N. (2010). Identifying common dynamic features in stock returns. Quantitative Finance, 10(7), 797-807. https://doi.org/10.1080/14697680903567152

Charles, A., \& Darné, O. (2014). Large shocks in the volatility of the Dow Jones Industrial Average index: 1928-2013. Journal of Banking \& Finance, 43, 188-199. https://doi.org/10.1016/j.jbankfin.2014.03.022

Chen, N., Roll, R., \& Ross, S. (1986). Economic Forces and the Stock Market. Journal of Business, 59, 383-403. https://doi.org/10.1086/296344

Engle, R. F. (1982). Autoregressive Conditional Heteroscedasticity with Estimates of the Variance of U.K. Inflation. Econometrica, 50, 987-1007. https://doi.org/10.2307/1912773

Engle, R. F., \& T. Bollerslev. (1986). Modeling the Persistence of Conditional Variances. Econometric Reviews, 5, 1-50. https://doi.org/10.1080/07474938608800095

Geske, R., \& R. Roll. (1983). The Monetary and Fiscal Linkage between Stock Returns and Inflation. Journal of Finance, 38, 1-33. https://doi.org/10.1111/j.1540-6261.1983.tb03623.x

Hamilton, J. D., \& R. Susmel. (1994). Autoregressive Conditional Heteroscedasticity and Changes in Regime. Journal of Econometrics, 64, 307-333. https://doi.org/10.1016/0304-4076(94)90067-1

Inclan, C., \& G. C. Tiao. (1994). Use of Cumulative Sums of Squares for Retrospective Detection of Changes of Variance. Journal of the American Statistical Association, 89, 913-923.

Lamoureux, C. G., \& W. D. Lastrapes. (1990). Persistence in Variance, Structural Change and the GARCH Model. Journal of Business and Economic Statistics, 68, 225-234.

Lastrapes, W. D. (1989). Exchange Rate Volatility and U.S. Monetary Policy: An ARCH Application. Journal of Money, Credit and Banking, 21, 66-77. https://doi.org/10.2307/1992578

Lee, B. S. (1992). Causal Relations among Stock Returns, Interest Rates, Real Activity, and Inflation. Journal of Finance, 47, 1591-603. https://doi.org/10.1111/j.1540-6261.1992.tb04673.x

Lobo, B. J. (2002). Large Changes in Major Exchange Rates: A Chronicle of the 1990s. Applied Financial Economics, 12, 805-811. https://doi.org/10.1080/09603100110088157

Malik, F. (2003). Sudden Changes in Variance and Volatility Persistence in Foreign Exchange Markets. Journal of Multinational Financial Management, 13, 217-230. https://doi.org/10.1016/S1042-444X(02)00052-X

Morales, L., \& Andreosso-O'Callaghan, B. (2014). Volatility analysis of precious metals returns and oil returns: An ICSS approach. Journal of Economics \& Finance, 38(3), 492-517. https://doi.org/10.1007/s12197-012-9229-8

Poterba, J. M., \& L. Summers. (1986). The Persistence of Volatility and Stock Market Fluctuations. American Economic Review, 76, 1143-1151.

Thorbecke, W. (1997). On Stock Market Returns and Monetary Policy. Journal of Finance, 52, 638-54. https://doi.org/10.1111/j.1540-6261.1997.tb04816.x

\section{Note}

Note 1. Bands at \pm 3 standard deviations, change points estimated using ICSS algorithm. 